\title{
Survey of pharmacist-managed primary care clinics using healthcare failure mode and effect analysis
}

\author{
Ashley H. VINCENT, Jasmine D. GONZALVO, Darin C. RAMSEY, Alison M. WALTON,
} Zachary A. WEBER, Jessica E. WILHOITE.

\begin{abstract}
${ }^{*}$
Objectives: The primary objective was to expand upon results of a previously piloted patient perception survey with Healthcare Failure Mode and Effect Analysis (HFMEA), to identify areas within pharmacist-managed clinics needing improvement. Methods: The survey was adapted for use in pharmacist-managed clinics. Patients completed the survey following regularly scheduled pharmacist appointments. Data were analyzed with a method adapted from HFMEA. Product scores could range from five to 25 . A product of five indicates that pharmacists are doing a good job on the items that patients place the most value on, while a product score of 25 indicates that pharmacists are doing a poor job. A score greater than or equal to ten was used to identify areas for improvement.
\end{abstract}

Results: Seventy-one patients completed surveys. Thirteen components were assessed and no item achieved a mean product greater than or equal to ten. The survey item with the highest mean product pertained to discussion of potential medication side effects (mean: 7.06; interquartile range: 5-10). Analysis of each survey item found that all survey items had multiple individual responses that provided a product score of greater than or equal to ten. The survey items most frequently listed in the overall population as being most valued were "Told you the name of each of your medicines and what they are used for", "Answered your questions fully," and "Explained what your medicines do".

Conclusions: Educational components provided during pharmacist-managed clinic appointments are

\footnotetext{
Ashley H. VINCENT. PharmD. College of Pharmacy, Purdue University; \& IU Health - Methodist, Adult Ambulatory Care Center. Indianapolis, IN (United States). Jasmine D. GONZALVO. PharmD. College of Pharmacy, Purdue University; \& Wishard Health Services, Ambulatory Care Pharmacy. Indianapolis, IN (United States). Darin C. RAMSEY. PharmD. College of Pharmacy and Health Sciences, Butler University; \& Primary Care Pharmacy, R.L. Roudebush VA Medical Center. Indianapolis, IN (United States).

Alison M. WALTON. PharmD. College of Pharmacy and Health Sciences, Butler University; \& Ambulatory Care Pharmacy, St. Vincent Health. Indianapolis, IN (United States).

Zachary A. WEBER. PharmD. College of Pharmacy, Purdue University. Primary Care Pharmacy, Wishard Health Services. Indianapolis, IN (United States). Jessica E. WILHOITE. PharmD. College of Pharmacy and Health Sciences, Butler University; \& Primary Care Pharmacy, St. Vincent Health. Indianapolis, IN (United States).
}

aligned with patients' needs and are successfully incorporating the components that patients value highly in a patient-healthcare provider interaction. The HFMEA model can be an important teaching tool to identify specific processes in need of improvement and to help enhance pharmacists' self-efficacy, which may further improve patient care.

Keywords: Pharmaceutical Services; Delivery of Health Care; Systems Analysis; Total Quality Management; United States

\section{ESTUDIO DE CONSULTAS DE ATENCIÓN PRIMARIA GESTIONADAS POR FARMACÉUTICOS USANDO EL ANÁLISIS DE MODOS Y EFECTOS DE FALLOS EN SALUD}

\section{RESUMEN}

Objetivos: El objetivo primario fue profundizar sobre los resultados de un cuestionario pre-pilotado de percepciones de los pacientes con el análisis de modos y efectos de fallos en salud (HFMEA) para identificar áreas en las que las consultas de farmacéuticas necesitan mejorar.

Métodos: El cuestionario fue adaptado para su uso en consultas farmacéuticas. Los pacientes cubrieron el cuestionario después de las citas farmacéuticas acordadas. Los datos se analizaron usando un método adaptado del HFMEA. Las puntuaciones de producto podían oscilar de 5 a 25 . Un producto de 5 indicaba que el farmacéutico estaba realizando un buen trabajo en los ítems que el paciente valorizaba más, mientras que una puntuación de 25 indicaba que el farmacéutico estaba haciendo un mal trabajo. Se utilizaron las puntuaciones de 10 o más para identificar áreas de mejoría.

Resultados: 71 pacientes completaron cuestionarios. Se evaluaron 33 componentes y ningún ítem alcanzó un producto medio mayor o igual a 10. El punto de la encuesta que alcanzó la media más alta trataba de la discusión de los potenciales efectos secundarios de la medicación (media: 7.06; rango intercuartilico: 5-10). El análisis de cada ítem del cuestionario encontró que todos los ítems tenían varias respuestas individuales que proporcionaban una puntuación igual o mayor de 10. Los ítems más frecuentemente considerados por la población total como siendo los más valorados fueron "le dijo el nombre de todos sus medicamentos y para que se usan", "respondió 
completamente sus preguntas" y "explico lo que hacen los medicamentos".

Conclusiones: Los componentes educativos proporcionados en las visitas a las consultas farmacéuticas se alinean con las necesidades de los pacientes e incorporan con éxito los componentes que los pacientes valoran más en la interacción paciente-profesional de la salud. El modelo HFMEA puede ser una importante herramienta educativa para identificar procesos específicos que necesitan mejorar y para ayudar a aumentar la autoeficacia de los farmacéuticos, lo que podrá en el futuro mejorar la atención a pacientes.

Palabras clave: Servicios Farmacéuticos; Prestación de Atención de Salud; Análisis de Sistemas; Gestión Total de la Calidad; Estados Unidos

\section{INTRODUCTION}

The recognition of pharmacists as healthcare providers in recent Medicare legislation is an important step in the expansion and acceptance of clinical pharmacy services. ${ }^{1}$ It has been widely accepted within pharmacy organizations that pharmaceutical care should be the focus of all pharmacists. $^{2}$ This emphasis on pharmaceutical care and pharmacist-patient interaction is also widely noted within regulations enacted by Congress. ${ }^{3,4}$ There are many documented benefits of pharmacist-managed care on disease outcomes ${ }^{5-}$ 9 , but information related to patient perceptions of pharmacist-managed care is lacking. As previously demonstrated by Gonzalvo and colleagues, there are consistent and emerging themes related to patient perceptions of pharmacist-managed care ${ }^{10}$, but there is limited guidance to help identify whether process improvement is needed in the clinical pharmacist-patient interaction. To compensate for the sparse amount of qualitative data relating to pharmacist-managed care, survey data have routinely been collected to determine patient satisfaction and perceptions of care. ${ }^{11,12}$

Recognizing the subjectivity of survey results, Healthcare Failure Mode and Effect Analysis (HFMEA) is a method that has been successfully implemented to add weight to the importance of survey responses by assigning numerical value. ${ }^{13}$ Traditionally, HFMEA has been used to proactively evaluate healthcare processes and identify areas for improvement or to enhance an existing service. Healthcare Failure Mode and Effect Analysis has also been used to identify a cause and effect relationship to reduce medication errors. ${ }^{14,15}$ HFMEA can provide a useful measure to improve clinical pharmacy services by identifying areas with the greatest impact based on what the patient values as important.

As opportunities for pharmacists continue to grow, those services offered must be evaluated to determine if they are consistent with what is valued by patients. The research noted by Knight and Caudill focused on a pharmacotherapy clinic at one Veterans Affairs Medical Center. ${ }^{13}$ This study builds upon their previous work by using the HFMEA model based on surveys of patients referred to the clinical pharmacist for disease state management across multiple pharmacist-managed clinics.

The primary objective of this multicenter study was to expand upon the results of a previously piloted patient perception survey with HFMEA ${ }^{13}$, to identify areas within pharmacist-managed clinics that need improvement based on patient perceptions.

\section{METHODS}

This study was conducted at six pharmacistmanaged clinics within the central Indiana region, with data collection occurring over a six-week period between January and June 2012. Pharmacistmanaged clinics were included based upon similarities in clinic location (i.e.; urban setting) and scope of clinical pharmacy services offered (i.e.; collaborative practice agreements for chronic disease management). Four of the six clinic sites generate patient charges for pharmacist appointments per their institution specific guidelines. Approval was obtained from each site's Institutional Review Board (IRB), and to maintain patient anonymity, no patient identifiers were recorded.

\section{Survey Development}

The survey utilized in this study was adapted with permission from a previously published patient perception survey and was adjusted for utilization in participating pharmacist-managed clinics. The survey was originally designed to measure patient perceptions of the quality of education provided at a single Veteran's Affairs institution. ${ }^{13}$ For the current study, the survey was expanded to incorporate a variety of pharmacist-managed clinics at multiple institutions across different health systems, to identify common areas of the pharmacist-patient interaction in need of improvement. Patients were instructed to respond based on only the medications and disease states managed by the pharmacist, not all medications and disease states.

\section{Survey Implementation}

The 27-item survey (online supplementary material) was distributed to six participating pharmacists for use in their pharmacist-managed clinic. Patients are referred to these pharmacist-managed clinics by their physicians for education and medication management. Each clinical pharmacist works closely with their patients and providers through a collaborative practice agreement to adjust therapies, obtain and assess necessary monitoring parameters, and help achieve desired therapeutic outcomes. The disease states managed were specific to each pharmacist-managed clinic and included anticoagulation, diabetes, hyperlipidemia, hypertension, smoking cessation, and general pharmacotherapy clinics. Patients presenting for routine follow-up in a participating pharmacistmanaged clinic were eligible for inclusion, while patients under 18 years of age, had less than two prior visits with the pharmacist, or who were unable to read English were excluded from the study. 


\begin{tabular}{|c|c|}
\hline Average age in years (SD) & $56(12)$ \\
\hline $\begin{array}{l}\text { Gender* } \\
\text { Male } \\
\text { Female }\end{array}$ & $\begin{array}{l}36(50.7 \%) \\
35(49.3 \%)\end{array}$ \\
\hline $\begin{array}{l}\text { Ethnicity* } \\
\text { Hispanic or Latino } \\
\text { Not Hispanic or Latino }\end{array}$ & $\begin{array}{c}1(1.4 \%) \\
70(98.6 \%)\end{array}$ \\
\hline $\begin{array}{l}\text { Race }^{\star *} \\
\text { American Indian/Alaska Native } \\
\text { Asian } \\
\text { Black/African American } \\
\text { Native Hawaiian/Pacific Islander } \\
\text { White/Caucasian }\end{array}$ & $\begin{array}{c}3(4 \%) \\
1(1.4 \%) \\
26(37.1 \%) \\
0 \\
40(57.1 \%) \\
\end{array}$ \\
\hline $\begin{array}{l}\text { No. of past pharmacist-managed clinic } \\
\text { visits* } \\
2 \\
3-4 \\
5-7 \\
8-10 \\
>10\end{array}$ & $\begin{array}{l}14(34.1 \%) \\
21(29.6 \%) \\
11(15.5 \%) \\
13(18.3 \%) \\
12(16.9 \%)\end{array}$ \\
\hline $\begin{array}{l}\text { Prescription Drug coverage }^{* * *} \\
\text { Institution specific } \\
\text { Medicaid/Medicare } \\
\text { Private } \\
\text { Cash/no third party }\end{array}$ & $\begin{array}{c}32(47.8 \%) \\
21(31.3 \%) \\
6(9.0 \%) \\
7(10.4 \%) \\
\end{array}$ \\
\hline $\begin{array}{l}\text { Total average no. of medications per } \\
\text { patient }(\mathrm{SD})^{+}\end{array}$ & $8.1(5.3)$ \\
\hline $\begin{array}{l}\text { Average no. of medications managed by } \\
\text { pharmacist per patient (SD) }\end{array}$ & $4.2(3.6)$ \\
\hline $\begin{array}{l}\text { Pharmacist-managed disease state* } \\
\text { Diabetes } \\
\text { Warfarin (Coumadin) management } \\
\text { High blood pressure } \\
\text { Quitting smoking } \\
\text { High cholesterol } \\
\text { Other }\end{array}$ & $\begin{array}{c}34(47.9 \%) \\
19(26.7 \%) \\
30(42.2 \%) \\
3(4.2 \%) \\
42(59.2 \%) \\
3(4.2 \%)^{\star \star \star \star}\end{array}$ \\
\hline $\begin{array}{l}\text { Duration of pharmacist-managed } \\
\text { disease state in years }(\mathrm{SD})^{++}\end{array}$ & $6.5(7.4)$ \\
\hline \multicolumn{2}{|c|}{$\begin{array}{l}{ }^{*} \mathrm{n}=71{ }^{* *} \mathrm{n}=70{ }^{* * *} \mathrm{n}=67^{+} \mathrm{n}=69{ }^{++} \mathrm{n}=65 \\
\text { multiple pharmacist-managed disease states }\end{array}$} \\
\hline
\end{tabular}

Eligible patients were recruited to participate immediately following a regularly scheduled appointment with the clinical pharmacist and were asked to complete the survey in the waiting room or empty exam room. Each patient was provided with written instructions, and completed surveys were given to reception staff within each clinic. The surveys were administered over a six week period to capture as many eligible patients as possible; however, each institution utilized a different six week period within the data collection period based on participating pharmacists' availability. Each eligible patient completed one survey during the six week study period, regardless of number of visits with the pharmacist during that time. There was no randomization or patient selection criteria other than the exclusion criteria previously defined.

\section{Statistical Analysis}

Data were analyzed with a method adapted from that used in a HFMEA process and with standard descriptive statistical methods, to examine quality improvement results. The HFMEA is a prospective assessment that provides a method for placing weights on outcomes (i.e.: assigning a value to the importance of various components of patient education based on what the patient feels is most important). This allows for results to be prioritized and easy identification of areas for improvement based on numerical scores. For this analysis, product scores could range from a score of five to 25 , with a product value of five indicating that pharmacists are doing a good job on the items that patients place the most value on while a product score of 25 would indicate that pharmacists are doing a poor job on the items that patients feel are most important. The specific steps used for calculating the HFMEA scores have been published previously ${ }^{13}$, and include scoring each survey component to be assessed, then multiplying corresponding components from sections 1 and 2 of the survey to determine an overall product score for that item. Traditionally, a product greater than onehalf of the highest score is used to indicate the need for improvement when using a HFMEA method. To maintain consistency with previously published methods, a conservative final score greater than or equal to 10 was used to identify areas for improvement across the pharmacist-managed clinic sites.

\section{RESULTS}

A total of 71 patients completed surveys during the data collection period. Fifty percent of survey respondents were male, with an average age of $56 \pm 12$ years (Table 1 ). Of the 13 components assessed, no item achieved a mean product of greater than or equal to ten (Table 2). Survey item 4, "Described the possible side effects of each of your medicines," had the highest overall mean product at 7.05. Analysis of each survey item found that all survey items had multiple individual responses that provided a product score of greater than or equal to ten (Figure 1). When evaluating the survey responses based on the specific disease state managed by the pharmacist, the patients with diabetes had the highest mean product for survey item 4 with a product score of 7.5. This score was lowest at 6.3 for patients seeing the clinical pharmacist for management of warfarin therapy. Survey item 5, "Provided information about your medical problems and the benefits of treating them", had the second highest overall mean product score

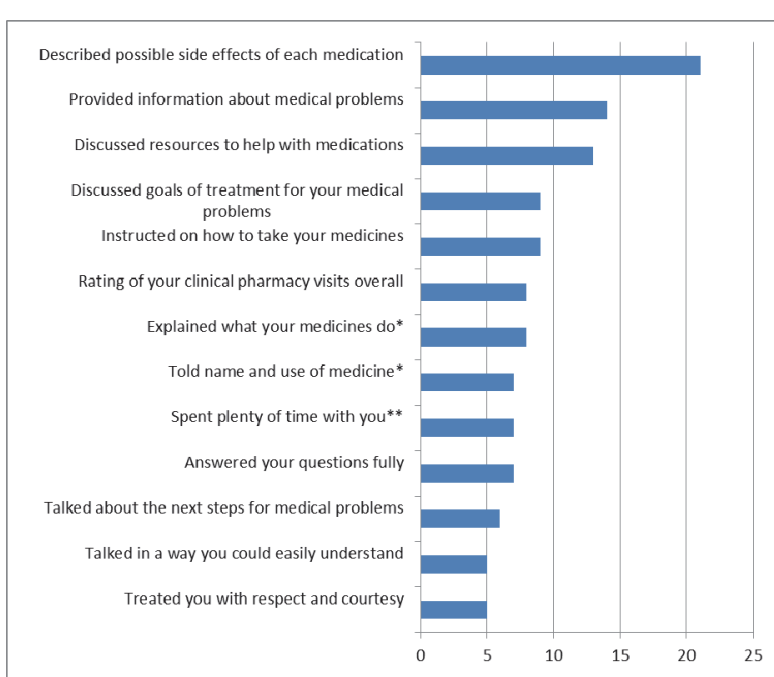

Figure 1. Number of Individual responses with product score $\geq 10(n=71){ }^{*} n=70 ;{ }^{* *} n=68$ 


\begin{tabular}{|l|c|}
\hline \multicolumn{1}{|c|}{ Table 2. Survey Results } \\
\hline \multicolumn{1}{|c|}{ Survey Item } & $\begin{array}{c}\text { Mean Product (IQ range) } \\
\mathrm{n}=71\end{array}$ \\
\hline 1. Told you the name of each of your medicines and what they are used for & $5.79(5-5)^{*}$ \\
\hline 2. Explained what your medicines do & $5.85(5-5)^{*}$ \\
\hline 3. Instructed you on how you should take your medicines & $5.83(5-10)$ \\
\hline 4. Described the possible side effects of each of your medicines & $7.06(5-10)$ \\
\hline 5. Provided information about your medical problems and the benefits of treating them & $6.31(5-8)$ \\
\hline 6. Discussed goals of treatment for each of your medical problems & $6.01(5-7)$ \\
\hline 7. Talked to you about the next steps in managing your medical problems & $6.07(5-7)$ \\
\hline 8. Answered your questions fully & $5.63(5-5)$ \\
\hline 9. Discussed the resources available to help you with your medications & $6.35(5-7)$ \\
\hline 10. Spent plenty of time with you & $5.69(5-5)^{* *}$ \\
\hline 11. Talked to you in a way you could easily understand & $5.41(5-5)$ \\
\hline 12. Treated you with respect and courtesy & $5.54(5-5)$ \\
\hline 13. Rating of your clinical pharmacy visits overall & $6.01(5-5)$ \\
\hline${ }^{*} \mathrm{n}=70 ;{ }^{* *} \mathrm{n}=68$ & \\
\hline
\end{tabular}

at 6.31. The mean product score was highest among patients seeing the pharmacist for hyperlipidemia management (mean $=6.5$ ) and lowest among patients seeing the pharmacist for warfarin management (mean=5.9). The majority of the remaining overall mean products were in the 5 to 6 point range.

The final non-demographic survey question asked patients to list three items they most valued. Of the 53 patients that responded, those items listed most often were "Told you the name of each of your medicines and what they are used for", "Answered your questions fully", and "Explained what your medicines do". The specific frequencies of response by survey item can be found in Table 3 . The six items most frequently listed as being "most valued" by patients all had a mean product $<5.9$. The frequency of the most valued educational components was compared between Males/Females (Figure 2) and African Americans/Caucasians (Figure 3). Males rated survey items 8 and 11 as most valued more often than females; females rated survey items 6,7 and 10 as most valued more often than males. African American participants rated survey items 4, 7, 10, and 12 more often than Caucasian participants; Caucasian participants more frequently rated survey items 1, 3, and 6 compared with African American participants.

\section{DISCUSSION}

The results obtained from this survey indicate that, collectively, clinical pharmacists are performing at a satisfactory level during each pharmacist-patient visit. No item achieved a product score high enough to be flagged as needing improvement based on HFMEA methods. Assessing the individual product scores has highlighted areas on which to focus future quality improvement efforts (i.e.: describing the possible side effects of each of medicine). Interestingly, these results, along with prior results ${ }^{13}$, found that the individual response most commonly associated with a score of greater than or equal to ten related to the discussion of potential medication side effects. This may indicate that pharmacists working in a pharmacist-managed clinic feel it is more important to focus on overall disease state management and perhaps assume that the pharmacist dispensing the prescription will educate the patient on the medication itself, including the possible side effects. Additionally, side effects may have been discussed when medication was initiated, but not emphasized at each patient visit if no medication changes were being made. Pharmacists working in pharmacist-managed clinics should develop ways to incorporate this educational component into patient interactions.

When looking at the items frequently marked as being the most valued by patients overall, the product scores indicate that clinical pharmacists are satisfying patients' expectations across a variety of pharmacist-managed clinic settings. However, when looking at specific patient populations there are some differences in what is valued most highly during an appointment with a clinical pharmacist. Male participants more strongly valued communication in a way that could be easily understood and that fully answered questions than the female participants. The female participants

\begin{tabular}{|l|c|}
\hline \multicolumn{1}{|c|}{ Table 3: Survey Responses Listed as 1 of 3 Most Valued Items } & $\begin{array}{c}\text { No. of Responses } \\
\mathrm{n}=53\end{array}$ \\
\hline & 26 \\
\hline Told you the name of each of your medicines and what they are used for & 24 \\
\hline Answered your questions fully & 18 \\
\hline Explained what your medicines do & 17 \\
\hline Treated you with respect and courtesy & 15 \\
\hline Instructed you on how you should take your medicines & 14 \\
\hline Talked to you in a way you could easily understand & 11 \\
\hline Described the possible side effects of each of your medicines & 11 \\
\hline Discussed goals of treatment for each of your medical problems & 7 \\
\hline Provided information about your medical problems and the benefits of treating them & 7 \\
\hline Talked to you about the next steps in managing your medical problems & 6 \\
\hline Spent plenty of time with you & 2 \\
\hline Discussed the resources available to help you with your medications & 1 \\
\hline Rating of your clinical pharmacy visits overall & \\
\hline
\end{tabular}




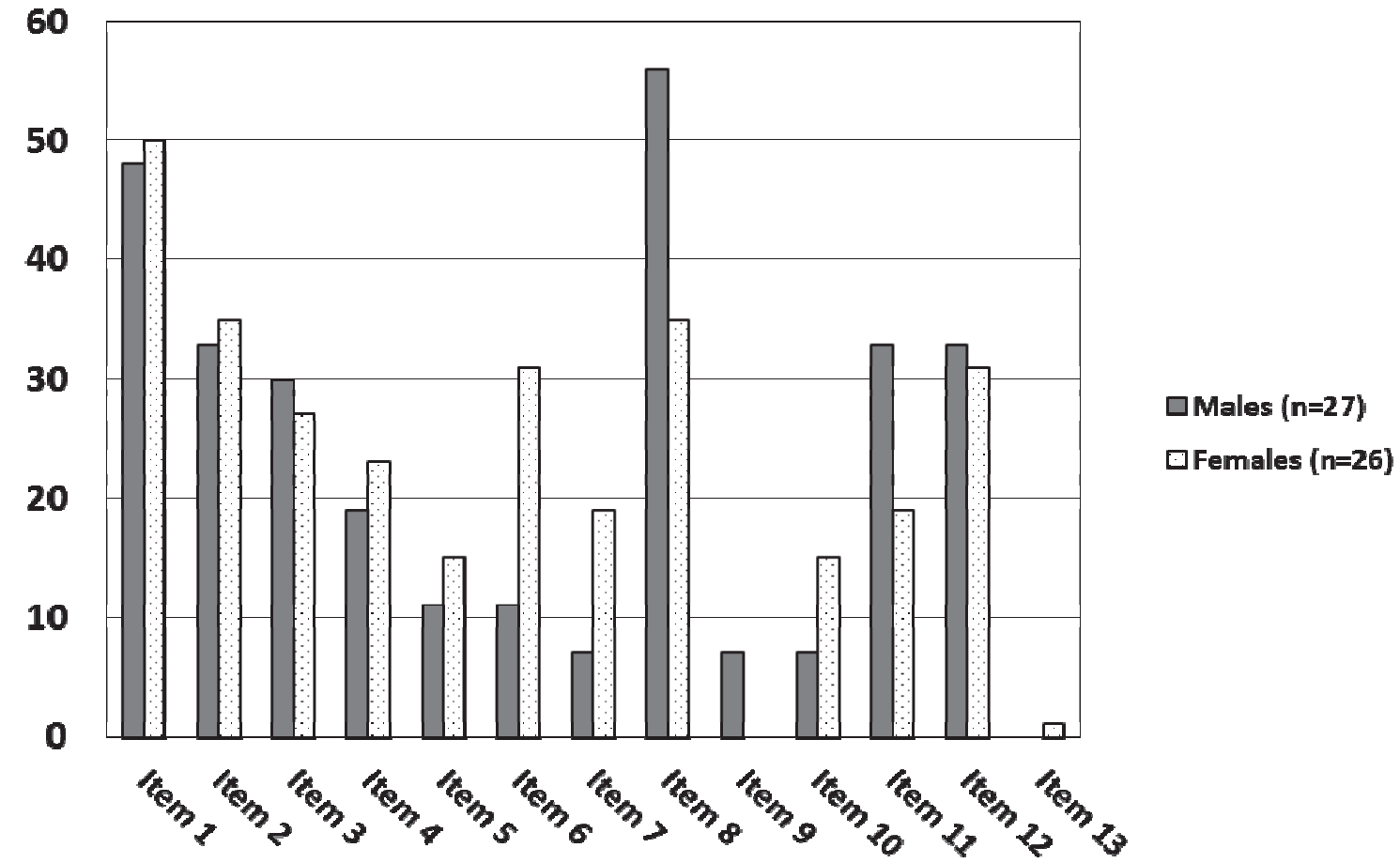

Figure 2. Survey responses listed as 1 of 3 most valued items (Males=27 / Females=26)

placed a higher value on discussing goals of treatment and next steps of therapy, along with spending plenty of time with the patient, than did the male participants. Additionally, African American participants more frequently ranked being treated with respect and courtesy as a highly valued appointment component than did Caucasian participants, while Caucasian participants more frequently ranked being told how to take their medications. These differences among patient populations illustrate the need for continued awareness on the part of the clinician in a pharmacist-managed clinic to ensure that each patient is getting the most out of their individual appointment by including components that are most likely to be highly valued.

The results found in this study are consistent with the previously published qualitative data on pharmacist-patient interactions ${ }^{10,13}$ and support the idea that disease state management by pharmacists is a successful extension of care for chronic diseases. Time constraints in primary care often limit the services that can be provided by

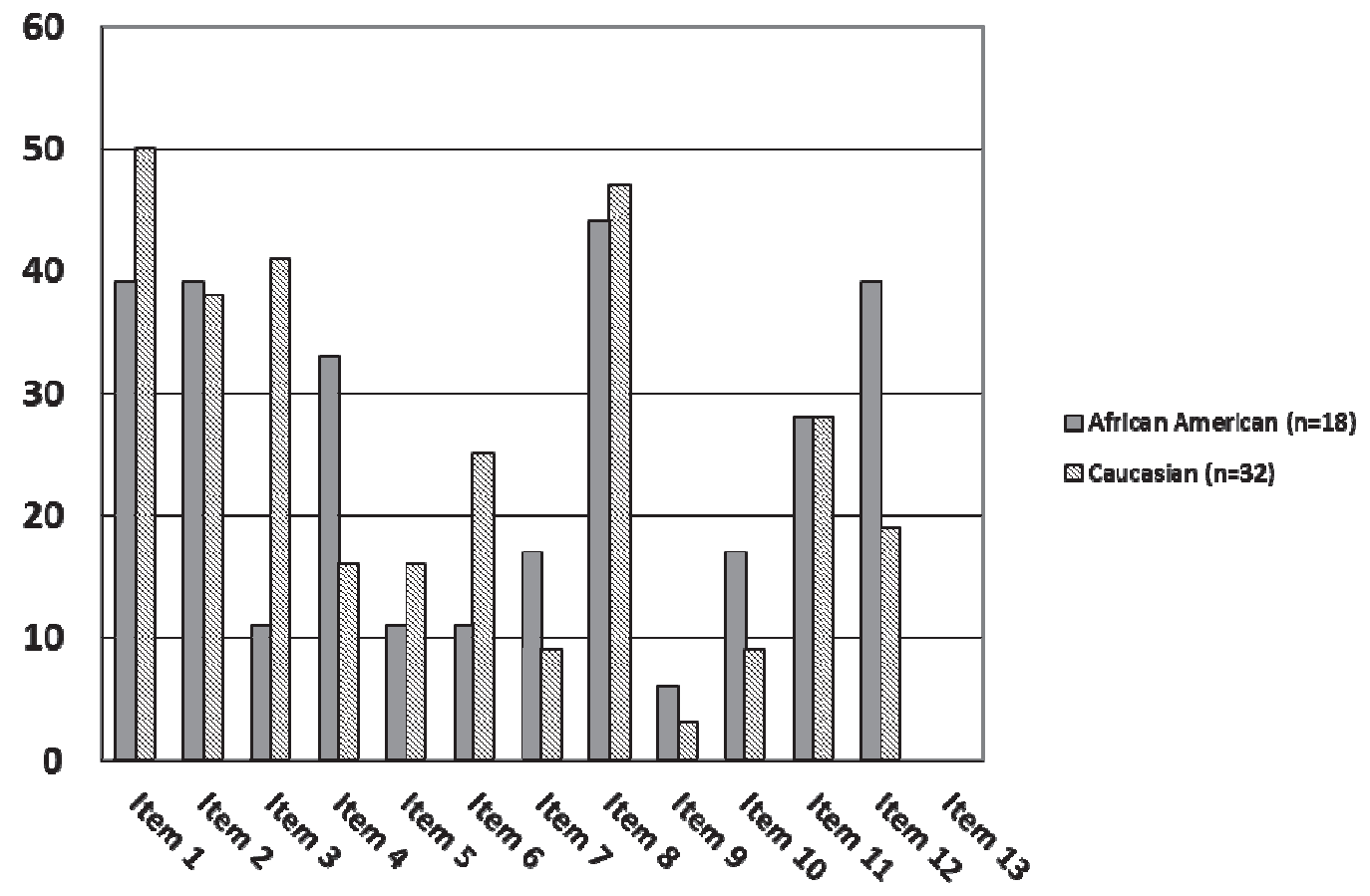

Figure 3: Survey Responses Listed as 1 of 3 Most Valued Items (African American=18 / Caucasian=32) 
physicians. ${ }^{16,17}$ Not only are pharmacists able to spend increased time with patients, but they are also able to do it in a way that often exceeds patient expectations of a patient-healthcare provider interaction.

The use of HFMEA as a clinical process improvement tool is a novel concept that can be applied to all aspects of pharmaceutical care, not just pharmacist-managed clinics. It is an important tool that can help pharmacists to identify areas of success as well as areas in need of improvement. An additional benefit to using the HFMEA model is its application as an important teaching tool to help increase pharmacists' self-efficacy, which may further improve patient care.

While the survey used in this research was originally designed to measure patient perceptions of the quality of pharmacist education provided at a single Veteran's Affairs institution affiliated clinics and found positive results in a small number of patients ${ }^{13}$, the current study expanded the survey distribution to incorporate a variety of pharmacistmanaged clinics at multiple institutions across different health systems, both Veteran's Affairs and non-Veteran's Affairs. The low number of overall participants in these studies highlights a larger challenge presented to pharmacist-managed clinics, the number of patients that do not keep their scheduled appointments. The survey was offered to each patient presenting to a pharmacist-managed clinic appointment during a six week period, unless they had already completed the survey. Patients were allowed to decline participation, but the majority of presenting patients chose to participate. The overall number of scheduled appointments during the six week survey period was significantly higher than 71. Many of the participating pharmacist-managed clinics had a patient no-show rate of greater than 50 percent, leading to a smaller than expected response rate.

The use of patient surveys as a research method is subjective by nature and open to bias. Steps were taken to minimize this bias by collecting data anonymously, allowing patients to skip questions they were not comfortable answering, and turning in completed surveys to non-pharmacy clinic staff. The study was not designed in a way to compare results between patients receiving pharmacistmanaged care, and those not receiving pharmacistmanaged care. As a result, no statements regarding the statistical significance of the data can be made; however, this does not limit the clinical significance or practical application of applying HFMEA results to identify areas that need improvement during a pharmacist-managed clinic appointment.

HFMEA scales are completely subjective in nature and item values are determined by those developing the scale. The authors attempted to limit subjectivity by using the same scale and analysis method that has been previously published. Additionally, HFMEA is intended to be used as a tool for process improvement. Each pharmacist's process may not be identical, introducing variables into the analysis. However, the items assessed by this survey are a part of each pharmacist-patient encounter and are similar across a variety of pharmacist-managed clinic settings. Based on the largely positive results obtained in this study, as well as the prior study by Knight and Caudill ${ }^{13}$, it should be considered whether or not the HFMEA tool is sensitive enough to identify areas in need of improvement in highly functioning pharmacistmanaged clinics. Further research involving both newly developed and well established pharmacistmanaged clinics should be conducted to test the sensitivity and validity of this HFMEA tool.

\section{CONCLUSIONS}

These results, combined with the results published by Knight and Caudill ${ }^{13}$, indicate that educational components provided during pharmacist-managed clinic appointments are aligned with patients' needs and clinic based pharmacists are able to successfully incorporate the components that patients value highly in a patient-healthcare provider interaction. The HFMEA model can be utilized as an important teaching tool to identify specific processes in need of improvement and to help enhance pharmacists' self-efficacy, which may further improve patient care.

\section{ACKNOWLEDGEMENTS}

The authors would like to thank Zina Shulman, PharmD for her work in survey adaptation and distribution and Kyle Hultgren, PharmD for contributing his HFMEA expertise.

\section{CONFLICT OF INTEREST}

All authors report no conflicts of interest.

\section{References}

1. American College of Clinical Pharmacy. HHS Regulation Expands Definition of Nonphysician Practitioners on Hospital Staffs - Includes Pharmacists. http://www.accp.com/announcements/hhsregulation.aspx (Accessed March 1, 2013).

2. American Society of Health-Systems Pharmacists Council on Professional Affairs. Draft statement on pharmaceutical care. Am J Hosp Pharm. 1993;50(1):126-128.

3. Barnett CW, Nykamp D, Ellington AM. Patient-Guided Counseling in the Community Pharmacy Setting. J Am Pharm Assoc (Wash). 2000;40(6):765-772.

4. Svarstad BL, Bultman DC, Mount JK. Patient Counseling Procided in Community Pharmacies: Effects of State Regulation, Pharmacist Age, and Busyness. J Am Pharm Assoc (2003). 2004;44(1):22-29.

5. Nkansah NT, Brewer JM, Connors R, Shermock KM. Clinical outcomes of patients with diabetes mellitus receiving medication management by pharmacists in an urban private physician practice. Am J Health Syst Pharm. 2008;65(2):145-149. doi: 10.2146/ajhp070012 
6. Jameson JP, Baty PJ. Pharmacist collaborative management of poorly controlled diabetes mellitus: a randomized controlled trial. Am J Manag Care. 2010;16(4):250-255.

7. Bex SD, Boldt AS, Needham SB, Bolf SM, Walston CM, Ramsey DC, Schmelz AN, Zillich AJ. Effectiveness of a hypertension care management program provided by clinical pharmacists for veterans. Pharmacotherapy. 2011;31(1):31-38. doi: 10.1592/phco.31.1.31

8. Till LT, Voris JC, Horst JB. Assessment of clinical pharmacist management of lipid-lowering therapy in a primary care setting. J Manag Care Pharm. 2003;9(3):269-273.

9. Rudd KM, Dier JG. Comparison of two different models of anticoagulation management services with usual medical care. Pharmacotherapy. 2010;30(4):330-338. doi: 10.1592/phco.30.4.330

10. Gonzalvo JD, Papineau EC, Ramsey DC, Vincent AH, Walton AM, Weber ZA, Wilhoite J. Patient Perceptions of Pharmacist-Managed Clinics: A Qualitative Analysis. J Pharm Technol. 2012;28(1):10-15.

11. Gourley GK, Gourley DR, La Monica Rigolosi E, Reed P, Solomon DK, Washington E. Development and validation of the pharmaceutical care satisfaction questionnaire. Am J Manag Care. 2001;7(5):461-466.

12. Larson LN, Rovers JP, MacKeigan LD. Patient satisfaction with pharmaceutical care: update of a validated instrument. J Am Pharm Assoc (Wash). 2002;42(1):44-50.

13. Knight $D E$, Caudill JA. Implementation of a patient perception survey in a pharmacist-managed primary care clinic and analysis with a unique HFMEA method. J Am Pharm Assoc (2003). 2010;50(1):78-83. doi: 10.1331/JAPhA.2010.08101

14. DeRosier J, Stalhandske E, Bagian JP, Nudell T. Using health care Failure Mode and Effect Analysis: the VA National Center for Patient Safety's prospective risk analysis system. Jt Comm J Qual Improv. 2002;28(5):248-267.

15. Kimehi-Woods J, Shultz JP. Using HFMEA to assess potential for patient harm from tubing misconnections. Jt Comm J Qual Patient Saf. 2006;32(7):373-381.

16. Yarnall KS, Pollak KI, Østbye T, Krause KM, Michener JL. Primary care: is there enough time for prevention? Am J Public Health. 2003;93(4):635-641.

17. Østbye T, Yarnall KS, Krause KM, Pollak KI, Gradison M, Michener JL. Is there time for management of patients with chronic diseases in primary care? Ann Fam Med. 2005;3(3):209-214. 